\title{
CLIL as a New Innovative Pedagogy: the Case of Russia and Armenia
}

\author{
Tatyana V. Sidorenko \\ Tomsk Polytechnic University \\ Margaret Apresyan \\ Yerevan State University
}

\begin{abstract}
The present paper presents teaching experience and observations in CLIL implementation of the countries that about forty years ago shared a common vision of how to teach foreign languages at the tertiary level, but since then have developed their education policies separately. The article suggests the analysis (based on the experimental activities) of Content and Language Integrated Learning (CLIL) from the perspectives of universities of two countries - Russia and Armenia. The analysis was carried out by means of an observation tool for CLIL teaching in Tomsk Polytechnic and Yerevan State Universities. In the overview the authors make the attempt to collect the general theoretical principles and concepts of CLIL, match them with the real classroom data that they have, analyze it and conclude what improvement is needed and what measures are eligible for the national educational context of both countries. The article data do not pretend to overview all the aspects of university language teaching, because they are different in the countries, they reflect to a certain extent the national teaching experience and relate it to the theoretical and practical issues of CLIL and ESP education.
\end{abstract}

Key words: Innovative pedagogy, Content and Language, Integrated Learning, principles and concepts of CLIL, educational concept. 


\section{Introduction}

In accordance with Bologna process requirements higher education all over the world aims at expanding educational and cultural boarders, fostering scientific research, integrating global experience, increasing the rate of academic mobility, enhancing the quality of learning and teaching, promoting the higher employability of graduates throughout their working lives. All these require competence in foreign language communication, on the development of which universities concentrate a large part of their resources and energies.

It is necessary to ascertain the fact that in spite of the time and resources invested before in foreign language education, the success rate, measured as communicatively competent foreign language user is still low. The shortcoming of it may be attributed to the fact that the language learnt in traditional foreign language classroom is often unrelated to real-life communication..." if input is predictable and output not spontaneous, how can we expect learners to be effective communicators if real-life communication is, just that, real" (Ting 2010).

For a long time ESP (English for Specific Purpose) has been recognized as the most popular approach to language teaching and learning at universities of Russia and Armenia. This approach would have remained as the effective one, unless the dynamism and challenges of our quickly changing time had not been long in coming. In terms of teaching resources deficiency (necessity to constant upgrading materials), time constrains and teaching staff training that is needed to enlarge its scope with new competences, the systems of higher education of the countries face the necessity to put some modifications into the existing teaching methods, making them more adjustable and flexible to respond the society and intellectual labour market demands.

The decision was seen in a relatively new approach for university pedagogy as Content and Language Integrated Learning (CLIL), where a foreign language is considered as the language of instruction in teaching subject-matter courses. We call this approach as a new one, because despite its "25 years history", CLIL remains in practice as "capricious" approach affected much with the national context, including the specificity of an educational system and even country- 
scaled goals. The ambivalence of the approach is also explained by the potential to be used for covering different purposes of different education stakeholders as students, subject and language teachers. Therefore, the search for the balance between them still remains as a point to discuss.

CLIL also brings with it one more complex challenge - the professional development of teachers who should understand how to organize their teaching, experiment with new approaches and put these into classroom practice. The latter will require the overhaul in on-going planning, monitoring and assessment, with clear goals and expectations. As much as CLIL, on the one hand, provides very positive encouragement to experiment, on the other hand, the evidence base or real classroom data upon which we can disseminate CLIL practice are quite limited. Much in CLIL is prompted with the national settings and "input factors" as resources and purposes of each university.

This paper makes not big but a timely contribution to both countries professional understanding of CLIL pedagogy and how it can be used at tertiary level currently or in prospect. It will consist of two main parts reflecting the outcomes of CLIL implementation initiatives in Russia and Armenia with describing national possibilities and priorities, and practices, if any. We deeply hope that our experience, rather small at moment, will provide a reader with some practical suggestions and raise issues for further reflections, particularly in terms of teaching models and teacher education programs without which the full potential of CLIL is unlikely to be realised and the approach will risk to be unsustainable.

\section{CLIL Prerequisites and History}

Initially, the approach originated as a form of bilingual education in Canada (province of Quebec) in the 1970s. Around 1965, a group of English speaking parents living in the French territory of Quebec, Canada, desired an educational kindergarten program for their children that would give them an equal opportunity a) to become competent to speak, read and write in English; b) to reach normal achievement levels throughout the curriculum, including 
the English language; c) to appreciate the traditions and culture of Frenchspeaking Canadians, as well as English-speaking Canadians" (Baker 1993:496).

They initiatively addressed their local educational authorities to solve this issue. Consequently, the solution in the form of programs aimed at creating the immersion environment for students in a language other than their mother tongue was developed and implemented also in other schools. On a voluntarily basis, the English-speaking children learnt school subjects in French (e.g. Mathematics or Geography) together with the French-speaking children. In the 1970s and 1980s the term "immersion" was used as a synonym of bilingual education. Later on, immersion programs designed for teaching the content in the non-native language without weakening the command of the mother tongue spread all over Canada, the United States and the rest of the world. Much later, in the early 2000s, CLIL's approach reached Europe, where it was seen as a new pedagogical philosophy, a means of linguistic consolidation of the society and a tool for multilingual development.

Historically, the term CLIL was introduced in 1994. By a researcher in the field of multilingual education, David Marsh, who at that time conducted an analysis of language education in Europe (The European Dimension: actions, trends, and foresight potentials). Then, in 2001, D. Marsh accumulated the experience and knowledge and described a methodology, the essence of which was to learn a foreign language as a tool for studying subject-matter courses. In the future, the practice of introducing bilingual education in Europe was implemented as a means to mitigate the problems associated with migration and multilinguism, but the practical implementation of this approach was carried out, mainly at the level of primary and secondary education.

\section{CLIL Methodology For and Against: General Insight}

\section{Why CLIL?}

With the growing interest in CLIL, there are some reflections on doubts and settings limitations regarding foreign language benefits in CLIL education because any benefits are attributable as much to: a) student selection (incoming level), b) subject complexity and other curriculum-based factors, and c) teacher 
awareness in methodology and their readiness to implement it. We will try to scrutinize the arguments in favour of CLIL with a consideration of the corresponding counter-arguments, while sounding a word of warning against the wholesale adoption of CLIL.

CLIL instruction has at times been constructed as a kind of catalyst for change in classroom pedagogies, implying that it somehow causes a shift from (traditional) teacher-centered practices to (more innovative) student-centered learning arrangements. Widely advertised as a "dual-focused approach" that gives equal attention to language and content (e.g., Mehisto, Marsh and Frigols 2008:9), CLIL can be described as an educational approach where curricular content, or part of it, is taught through the medium of a foreign language, typically to students participating in some form of mainstream education at the primary, secondary, or tertiary level (Puffer 2011).

As we can see from the recent surveys (Pérez-Cañado 2011), CLIL is clearly on its way to becoming obligation, not an option, for tertiary education. Against the background of internationalization and globalization perspectives, educational institutions face the need to create borderless education that entails the challenge of programme competitiveness and language acquisition. CLIL is considered as a driver for both.

And what makes CLIL so attractive in current pedagogy (mainly focused on foreign language teaching) is that the content is expected to give the use of the foreign language a communicative purpose so "In this sense CLIL is the ultimate dream of Communicative Language Teaching (e.g. Brumfit and Johnson 1979) and Task Based Learning (e.g. Willis 1996) rolled into one: ..." (Puffer 2007). Much CLIL research, then, while clearly following more sophisticated conceptual orientations than policy papers, still tends to share the position that CLIL classrooms are somehow fundamentally different from foreign language lessons.

CLIL is often understood as an educational model for content where the classroom provides the only site for learners' interaction in the target language. Therefore, CLIL is about either foreign language or lingua franca. This means that CLIL lessons are usually timetabled as content lessons (e.g., biology, music, 
geography, mechanical engineering), while the target language normally continues as a subject in its own right in the shape of foreign language lessons taught by language specialists. For these reasons CLIL implies that teachers will normally be non-native speakers of the target language. They are not, in most cases, foreign language experts, but instead content experts, because "classroom content is not so much taken from everyday life or the general content of the target language" (Puffer 2007).

This model can be complicated by the fact that teaching in a foreign language can be affected by learners' knowledge, skills, and understanding of the subject because the medium of learning is less perfectly known than to students in terms of a language and this will lead to reduced subject competence and to detrimental of subject knowledge. Another fear that can be pointed out in this context is that CLIL teachers, among subject experts, will not have the required level in language proficiency and due to this reason will simplify the content of teaching, making this subject knowledge reduced. In this vein, the obvious CLIL courses benefits will be in foreign language enhancement, while the weaker point is content capacities low-speed development.

Research on the issue has been difficult to carry out because relatively few countries conduct standardized testing in science and social studies subjects. Thus ready-made constructs of subject-specific competence in a particular area are hard to come by, making quantitative surveys and cross-country comparisons more problematic than those regarding language attainment. Therefore, the definition of CLIL as a dual-focused approach has to be regarded as programmatic rather than factual, and practices that are "content-oriented but language sensitive" (Wolff 2007:17) cannot be regarded as firmly established.

For the time being, there are views that consider CLIL as a very reliable approach with less pain for the learners. It is worth asking the question what assumptions lie behind such expectations. These implicit baseline assumptions are in line with Krashen's (1985) monitor model, which continues to be the most prominent reception-based theory of language acquisition outside 
academic research circles. As is well known, the basic idea of the model is that if the language learner is exposed to comprehensible input, acquisition will occur, especially if the learning situation is characterized by positive emotions. The latter condition is widely thought to be fulfilled in CLIL by virtue of the fact that language mistakes are supposedly neither penalized nor corrected in CLIL classrooms.

Applied linguistic research into CLIL has, naturally, made use of a wider theoretical base than this, starting with a focus on interaction (Long 1996). A first approximation was formulated by Gajo (2007) who suggested that "the notion of integration [of language and content] implies precise reflection on the linguistic aspect of subject knowledge and on the role of discourse in the learning process" (p. 568). Another important theoretical influence has been Swain's output hypothesis (1995) and its claim that only the self-regulated production of utterances that encode learners' intended meanings forces them to actively process morphosyntactic aspects of the foreign language, thereby expanding their active linguistic repertoire and achieving deeper entrenchment of what they already know.

And to carry on with CLIL efficiency, it is worthwhile speaking about interactive knowledge-construction processes and how they influence the work of our brain. On CLIL as a brain activator much was told by Teresa Ting (20082018), the expert in neuroscience. In her paper "Examples from CLILneuroscience" she says: CLIL automatically change classroom dynamics - rather than downloading information onto passive learners, teachers guide them towards deep-level understanding of concepts through interactive knowledgeconstruction processes. Such active learning is coherent with how the brain learns (Ting 2010). Then, she continues: the efficacy approaching science (content knowledge) through CLIL is explained by the fact that memory formation does not occur in isolation but is tightly linked to the neurobiological processes of fear, motivation and executive control. The main aspect of successful CLIL education, if done well, is right balance in complexity between language and content teaching. The concepts complexity or learning load in CLIL can seem very high, taking into consideration the double difficulty - 
science-based concepts and knowledge and the second language as a language of instructions. This can bring some additional fears to learners and will put the barriers and lead to brain refusal to work with the information.

The American Association for the Advancement of Science (1989) and the National Research Council (1996) warn that, in "overemphasizing facts", rather than helping learners cultivate a deep-level understanding of scientific concepts, science curricula inadvertently oblige teachers to download onto learners facts and formulas to explain odd-sounding terminology of phenomena that learners can neither see nor appreciate. Worse still, if these details are embedded into the "alienating language of science", children quickly come to believe that science is for the brainy few, propagating the opinion that "science is inaccessible and thus irrelevant for the general public" (Halliday and Martin 1993). In other words, no matter the complexity of concepts, the tasks offered to learners to deal with are to be solvable, the learning context should be more brain-aware or brain compatible and the didactic objective number one is to find this proper balance in practice.

Hence, the specific nature of CLIL courses is the right balance between the difficulty of content and language. This balance can be achieved by careful planning and selection of content that has a linguistic potential, as well as a simultaneous selection of language that is most typical for a professional field (Ting 2011). In other words, CLIL = simple content + complex language or CLIL = complex content + simple language. That is, the increase in linguistic complexity should be compensated by a decrease in professional content complexity and vice versa. Therefore, CLIL implies changes to the traditional repertories of language and non-language teachers, requiring the development of a special approach where educators work collaboratively to formulate new didactics for "a real integration and function in language teaching" (Marsh 2008).

Concerns with theorizing the interaction of language and content are currently becoming a focus of attention for CLIL researchers. Given equal importance to both content and language (Marsh and Marsland 1999), CLIL advocates a 50:50/Content:Language CLIL-equilibrium where the 50:Language 
component refers to the learners' language. The central element in the success of CLIL (Ting 2010) is that it elicits language from the learner, not the teacher. If $50 \%$ of the learning time is devoted to developing learner's language, it is clear that the era of teacher-as-talking-encyclopedia must give way to more student-centered science education: CLIL automatically advocates "learning by construction rather than learning by instructions" (Marsh 2009). Moreover, as CLIL advocates content-learning not in a foreign language but through a foreign language (Marsh 2005), educators are called upon to design activities in which language is used in an authentically purposeful search for understanding. Done right, CLIL classroom are thus student-centered and investigative, very much in line with "neuroscience of learning".

The brain-compatible learning environment can be created if the fear level is decreased, whereas the motivation level is increased. The 50:50 CLIL learning environment is easily accommodated with the following filters, which enable to make the environment not only brain-compatible but investigative and interactive. There are 5 filters in total:

a) the novelty filter: is the information new?

b) the pleasantness filter: is the input enjoyable?

c) the relevance filter: what does this have to do with my goal - do I need it - is it significant?

d) the cope-ability filter: can I understand this?

e) the self-social image filter: will knowing this make me "cool"?

Even so, it is clear that much more work needs to be done conceptually and empirically across different contexts for CLIL classroom methodology until CLIL concepts can be regarded as settled. At the present stage CLIL classrooms share a great deal more with traditional language lessons, in most cases making them language-led in subject-matter discourse. And in these cases there is nothing to differ CLIL methodology from the ESP one and it is still the point for many universities to discuss and analyse.

In summarizing CLIL advantages and conclusions regarding its "undisputable" efficacy with the accent to the evidence that content-based situations help steer learners' attention from language forms to things 
accomplished and meanings conveyed through language, making by this the right-balanced language-learning environment, which is the keystone for CLIL success, nevertheless, we assert that CLIL is not a panacea.

\section{Why not CLIL?}

As considered above, CLIL is an approach to learning oriented towards achievement of a dual objective, where a foreign language is used as a means of teaching content and at the same time as the object of study. The efficacy of CLIL education has been already proved but by the same token currently we observe a diverse interpretation of CLIL methodology that is mostly affected by the difference in national and cultural contexts. What plays well in one setting, can have a counter effect in another one, just due to different input conditions and goals. Answering the question why not CLIL we find the following reasoning.

Smith (2005) asks the pertinent question: "So why are we witnessing this quest to use a foreign language as the medium of instruction - trying to make the unnatural natural?" In a somewhat similar vein, Mehisto, Marsh and Frigols (2008) state somewhat rhetorically that "Common sense seems to say that students studying in a second language cannot possibly learn the same amount of content as students studying in their first language" (Puffer 2011).

Some European CLIL proponents emphasise a language over context (Coyle 2007:548), and "subject matter pedagogies and their integration with language pedagogies are being systematically overlooked". Wiesemes (2009) noted the high face validity of CLIL but also warned against CLIL becoming a trend or buzz word and nothing more because the lack of research base. He wrote "the political support for CLIL teaching is generally strong, concrete guidance and support for teachers implementing it are largely absent" (Wiesemes 2009:16).

The apparent attraction of CLIL, and some content-based (immersion) programmes (Cammarata and Tedick 2012; Wesche 2010), is that the students get two for the price of one (Puffer, Nikula and Smit 2010; Zydatiß 2012): subject content and foreign language development simultaneously and interdependently. But in this there are some underwater stones and on it 
Bruton (2013) made the quite ironic conclusion that the fundamental argument for simultaneous content and foreign language learning relies on a "two-for-the price-of-one" (p. 588) perspective, which is often very attractive but can result in unfortunate, unintended consequences. Concerning the learning of content, for example, he suggested "it would be possible to have the opposite, 1/2-for-2" result. Mostly it is explained by the complexity of CLIL methodology, if done right, including special CLIL teachers training that will be targeted at CLIL (not ESP methodology) teaching materials and other didactic instrumentation development. The subject-teachers competence for CLIL is very important because "if the content teaching is already below expected standards, as it seems to be in Andalusia in Spain, CLIL is probably not going to help, except for cases where there has been selection, in which case the overall averages might decrease. In Germany, Breidbach and Viebrock (2012) suggest that "structural selectivity of CLIL appears to have a greater impact on student achievement than CLIL itself has on student achievement" (Bruton 2011).

Whether CLIL is ultimately beneficial or not will depend on a number of contributing factors, but nobody will deny that CLIL is hard work for teachers, and it is no easy matter for students to advance in subject matter at the same time as in the foreign language (Coonan 2007). Very often the content is not only no help for the language development, but the lack of language might be a serious handicap and hindrance for content development (Apsel 2012), if the foreign language is the real medium of instruction. Furthermore, interaction in the foreign language is very often absent, and translation and first language use not atypical (Mehisto 2008; Tan 2011). In such cases there may be a need for extra foreign language support, which conflicts with the 2-for-1 formula. Coonan (2007), actually documents the fact that this difficulty can be beneficial as content teachers might make more effort to make the subject-matter accessible, which might in turn influence their teaching in a native language. Even so, if the students have problems with the content, it may be difficult for them to find help at home in a foreign language medium, especially in languages other than English, unless the same content is also available in their 
native language. Drop outs are another element of CLIL that are conveniently ignored (Apsel 2012).

\section{CLIL Practice at Tomsk Polytechnic University, Russia (2011-2017)}

The CLIL story of Tomsk Polytechnic University we would like to preface with Charles Darwin's quotation: "It is not the strongest of the species that survives, nor the most intelligent, but rather the most responsive to change". This is absolutely true that the need to respond the challenges of the time was the main motive to launch CLIL education in the form of separate courses in our university. Here are some details.

Starting from 2011, RF national policies consider the language competence not only as a component of professional qualification of an engineer, but also as a tool to globalize and internationalize universities, to promote universities into international community (Чучалин, Велединская, Ройз; 2004). The new national education strategy required some strong initiatives from the university management including new solutions in language education. University language policies reacted appropriately. The new “TPU Roadmap 2020” aims among others to create a comfortable bilingual environment, which should contribute to a significant increase in the population of international students and activate teachers' and students' participation in international research carried out by the world's leading centres (<http://tpu.ru/today/programs/viu $>$ ).

The available resources were reformulated into a new CLIL-based course of Professional Training/course in a Foreign Language to support the reformed ideology. The new course inherited the significant teaching experience and the methodology, as well as materials accumulated by that time. However, the following question provoked the debate when new disciplines were put into practice: Which language level should teachers possess to be able to deliver a CLIL course? Can this course repeat some content previously learned in the Russian language? What should be the nature of cooperation between language and content departments? What are the criteria to select teaching and learning material? How can a students' low language level be compensated?

Many of the questions above remain open until present day. 


\section{Materials and Methods}

As we have already said - CLIL is debated much but it has not been welltermed yet and has the lack of practice base. All this is compounded by differences in cultural backgrounds and social-educational patterns, established in each country. "There is no single blueprint of content and language integration that could be applied in the same way in different countries - no model is for export" (Marsh 2011); "CLIL resembles acupuncture: it works but nobody seems to know why" (Van de Craen, Mondt, Allain, Gao 2007); "the political support for CLIL teaching is generally strong, concrete guidance and support for teachers implementing it are largely absent" (Wiesemes 2009).

Thus, CLIL courses replaced the ESP courses and interdisciplinary tandems, involving both language teacher and subject teacher in delivering one course. These tandems were unique by nature and, virtually, had no analogues in the Russian higher education system.

Interdisciplinary tandems emerged in the practice of TPU in 2008 and existed until 2011. The main intended purpose of tandems was the collaboration of subject teachers and language teachers within one course. Responsibility was distributed in accordance with the competences of teachers in the way that language teachers were responsible for the language component, while subject teachers were in charge of the subject knowledge delivering and skills development. Such training was specified by the narrow professional scope of the courses, namely, a specific purpose was determined by a definite knowledge area, for example, not just Information Technology and Biomedicine, but "Databases" and "Nanocomposite Polymer Materials", etc.

No doubt, this approach lies in the "kingdom" of the ESP approach and fully adopts its methodology but at the same time it has a more precise content based on "special purpose". However, there arises a question: "What prompted the university to move to a new level of this approach understanding?" The answer is rather simple, the university was triggered to make such a decision due to dissatisfaction with learning outcomes, which, according to a preliminary hypothesis, was the consequence of the limitations concerning the proposed learning context and context-based language forms that were chosen 
as the teaching basis by language teachers, who did not have engineering education. It was confined to the formation of common professionally oriented skills and knowledge. In other words, the discussion of professional topics was reduced to the problems stating under the conditions of inability to find practical solutions.

The effectiveness of the tandems was obvious; however, the massive introduction of such courses in the educational process required a significant increase in the time resource for the training materials development and implementation. In addition, this practice failed to provide the desired degree of sustainability while its effectiveness depended on a certain level of language proficiency (B2) of subject teachers.

Thus, the university had to abandon the "expensive" approach of tandems and make another attempt to optimize the resource and maximize performance by integrating subject and linguistic competencies as well as knowledge and to begin its CLIL history. Consequently, by the time CLIL courses were introduced in the person of subject teachers the university already had quite much experience in delivering subjects in a foreign language. Accordingly, there was also a certain toolkit of methodological practices, including those created with the help of linguists (language teachers).

The transmission to CLIL-based teaching is not so easy. The main reason for it is that the approach has not been well-termed yet for the Russian context and has the lack of practice base. In spite of its rather "long existence" in the world pedagogy, CLIL application is compounded with some differences in cultural backgrounds and social-educational patterns established in the countries of the world. We need first to identify 1) the degree of the approach appropriateness to our settings and 2) the reasons preventing its implementation.

With the objective to find out whether Russian universities understand how CLIL training should be structured and what methodology the approach has we conducted a survey among the subject teachers currently engaged in 
CLIL in order to get a general impression of their satisfaction and understanding of the didactic goals they are to reach, and tasks they are to accomplish.

\section{Survey Results (Russia)}

The survey comprised 35 subject teachers of TPU. The survey findings have indicated that the majority of the respondents are not satisfied with the conditions of teaching the subject in a foreign language, due to the fact that $50 \%$ of the respondents consider themselves to be insufficiently aware of the CLIL methodology and procedure, the goal of training, and what should be assessed.

The mentioned obstacles preventing efficient implementation of CLIL were as follows:

- different levels of students' foreign language proficiency;

- low motivation of students to study disciplines in a foreign language;

- lack of opportunity to prepare course materials with the assistance of a language teacher/native speaker;

- lack of ready-to-use materials;

- lack of guidelines for assessing the knowledge of the students enrolled in CLIL courses;

- inconsistency of opinions concerning the understanding of the learning objective;

- insufficient levels of a foreign language among the subject teachers.

The respondents put forward the following potential ways of solving the problem:

- to provide the opportunity to study CLIL-techniques;

- to develop interaction with language teachers to receive assistance in selecting and producing educational material;

- to develop the programs of language internships abroad in order to support the language level;

- to encourage interaction through workshops and meetings with the peers engaged in CLIL training. 
Here is some statistics: $25 \%$ of subject teachers produce the teaching materials with the language teachers' assistance; $50 \%$ of respondents use the study guides previously developed during the tandem practices; $20 \%$ use ESP materials; $20 \%$ develop materials by themselves on the basis of authentic text materials within the scope of the subject area.

$50 \%$ of teachers choose technical translation as the main type of educational activities; $20 \%$ predominantly focus their courses on introduction and drilling terminology; $20 \%$ emphasize the practice of speaking in the form of presentations and discussions; $10 \%$ give priority to writing articles.

The following learning objectives were highlighted (in the descending order):

- expansion of subject knowledge through the use of literature in English and information resources,

- study of terminology,

- development of writing skills by writing reports and articles, including translation.

As we can judge, the described situation does not quite correlate with the priority activities chosen by the teachers (the statistics is presented above).

The survey findings indicate that the current CLIL practice is ambiguous with regards to understanding the learning objectives and the function of a teacher. As a matter of course, the purpose of training can be the expansion of the subject area through the use of English sources. However, this formulation does not present the teaching goal to learn a foreign language (the second goal, but not less important than the first one). Also, the terminology of a subject area in the form of a separate subject knowledge domain is not quite justified to serve the purpose of the CLIL course because it cannot be considered separately and only the list of terms can be studied.

Regarding writing which includes terminology as well, it is unlikely that the involvement of a subject teacher in the education process would be appropriate due to the lack of the required qualifications and methodological knowledge for this. In this case, the replacement of a language teacher is not justified. Technical translation is a special field of knowledge and, accordingly, 
delivering this material will require certain competencies that are not completely identical to the merely practical skills of subject teachers which they use in their professional activities. Thus, the above facts indicate the following:

1) CLIL courses are organized according to the principle "I am involved in CLIL training because I know a foreign language",

2) CLIL methodology is not clearly used in practice, thus, understanding of CLIL methodology is questioned,

3) CLIL training materials are developed with no regard to the principles of the approach but are lectures translated into a foreign language.

Consequently, after analyzing the survey findings we became concerned with the requirements and conditions necessary for successful implementation of CLIL training. Thus, we have attempted to systematize the preliminary study outcomes determining the effectiveness of the approach for university education. Therefore, we assume that CLIL training requires the following:

a) motivated teaching staff feeling no fear about using new forms and teaching tools;

b) a qualified teaching staff having the set of competencies required for implementing CLIL training;

c) possibility of obtaining additional competences in the field of CLIL pedagogy through advanced training programs;

d) motivated students who understand the importance of a foreign language for building and developing the overall competence of an engineer;

e) peer professional communities that discuss current issues related to CLIL training procedure;

f) availability of a university-wide CLIL training conception performing the regulatory function of processes.

\section{CLIL Practice at Yerevan State University}

Armenia definitely shares the opinion that CLIL approach can significantly improve the level of internationalization in the country, particularly in the field of higher education. Thus, the approach is viewed as a new pedagogic 
technology capable of improving the efficiency of educational system at management, content and motivation levels.

As for CLIL in Armenia, its implementation is currently episodic and, if implemented, is only partial, in single educational institutions. The problem is that the absence of a single scientific and methodological guidance on the nature, objectives and possibilities of the approach, and most importantly the lack of available mastering practices hampers the effective implementation of CLIL education in the country.

It should be noted that in Armenia more and more publications have been devoted to CLIL approach recently, which proves the high interest of the scientific community in the development of this direction at all levels of the educational system. However, Armenia cannot fully accept and adopt the practices and techniques developed in the countries of the European Union or the American continent, whose higher level of development is due to the earlier identification of linguistic, social and political needs for the consolidated and sustainable growth of the society. In Armenia's case, as in case with Russia, the CLIL education needs to be preliminarily analyzed and tailored up with the conditions involving the national context and country needs.

Armenia reckons that for the effective implementation of the CLIL approach in the perspective of Armenian higher education system, it is necessary to: 1) develop a concept of its implementation, taking into account national specificity of the educational system, 2) work out an adaptive methodology and 3) design programs for academic staff involved in CLIL instruction.

To develop the concept and methodology of CLIL-instruction in the Armenian universities, Yerevan State University initiated the project - New CLIL for Armenia - where the theories and practices existing at the moment in the foreign and Armenian realities will be analyzed with the aim to obtain the data to be used further in composing graphical matrix describing inputs and outputs for the national CLIL models.

The following methods and approaches will be used to carry out the indicated algorithm: 
General scientific: Analysis of methodological and pedagogical literature on the research problem; Comparative analysis of existing practices for the implementation of CLIL instruction in Armenian and foreign universities; Analysis and description of the conditions of the Armenian higher education system, influencing the implementation of the approach; Analysis of national educational requirements and development of measures to meet those requirements using the CLIL approach.

Systematic: Systematic presentation of the approach and its tools as a model, determining the key positions and principles of the CLIL concept for the Armenian education system.

Pedagogical and interdisciplinary: Development of methods, practices and pedagogical strategies when designing CLIL-courses and materials and their further approbation.

Pedagogical design: Development of materials and methods of presentation, improving the mental activity and the level of perception;

Empirical: Approbation of CLIL-instruction in Armenian universities: study and overview of practical experience, adjustments

Statistical: surveys, interviews; data processing, quantitative and qualitative analysis of the approbation results.

\section{Survey Results (Armenia)}

As mentioned above, CLIL practices in Armenia are still of episodic character that impedes to collect more or less objective opinions of stakeholders involved. We initiated two attempts at Yerevan State University to conduct surveys through Google Forms on CLIL outcomes and ESP outcomes. The latter due to long practice turned to be more illustrative and for this reason it is a subject for analysis. The survey comprised 14 language teachers. The most part of them have had the ESP experience (75\%) more than 10 years, working with the language for specific purposes in such areas as: math, social studies, law, chemistry, psychology, business, etc. There is no divergence of views regarding the understanding of the word PURPOSE in ESP teaching. Practically, this is the point where the general principles of language meet with those of subject 
area: meet the need of students to run professional communication in real job world.

Among the THREE things that language teachers enjoy most in ESP practice are: innovativeness, specific terminology, interdisiplinarity and academic freedom in choosing authentic materials. Among THREE biggest challenges in ESP teaching they named - lack of specialized knowledge (content/subject), technology deficiency, and a limited number of hours.

What the Armenian language teachers miss in ESP methodology is real life language skills, and this restricts their teaching practices and puts some limits on teaching freedom. Despite the opinions illustrating "the lack of professionbased knowledge", 100\% of respondents stated that they do not feel the lack in qualification or the need in some additional training to work in ESP environment, although $75 \%$ of ESP teachers did not study any professional courses for doing ESP, they gained the knowledge on how to do it in the process of teaching.

The teachers pointed out - the application of digital media and new technologies in pedagogy as a means to improve the teaching performance. Generally, ESP teachers in Armenia are satisfied with how ESP is organized but they called upon THREE weak points in assessing standards: too much stress on summative assessment while formative assessment is neglected; too little differentiation that would support students of different language level; too much standardization that does not work in class.

\section{Conclusion}

It is evident that different pedagogical approaches appear in response to emerging professional and social needs and challenges. The application of ESP and CLIL at Yerevan and Tomsk universities do not allow deciding which one is better. The choice is determined by goals and available resources (human and material). The main principle in choosing is feasibility and applicability at a place. There is no need to start CLIL if you do not have the resource or special need for it, the chase for being innovative can lead to the results with the "sign minus". Meanwhile, if ESP is a well-established practice and complies with the 
university policy and curricula, there is no need to replace it with new "more innovative" approaches.

Nevertheless, CLIL as a new and younger methodology compared to ESP needs to be worded in explicit terms and expanded with richer practices based on the national standards and cultural settings. CLIL multinational pool collected in collaborations is capable to guarantee the Best Practice transferability.

\section{References:}

1. Apresyan, M. (2007) "Are There Any CLIL Schools in Armenia?"// "Windows on CLIL" Content and Language integrated learning in the European Spotlight. Graz, Austria.

2. Apsel, C. (2012) Coping with CLIL: Dropouts from CLIL Streams in Germany. // International CLIL Research Journal, 1(4), 47-56. Available at: $<$ http://www.icrj.eu/14/article5.html> [Accessed May 2017].

3. Baker, C. (1993) Foundations of Bilingual Education and bilingualism. Clevedon, UK: Multilingual Matters.

4. Bruton, A. (2011) Is CLIL so Beneficial, or Just Selective? Re-Evaluating Some of the Research. System, 39/4, pp. 523-532.

5. Bruton, A. (2013) CLIL. Some of the Reasons Why ... and Why not. // System 41, pp. 587-597. Centraal Bureau voor de Statistiek (2013). Available at: <http://www.cbs.nl/nlNL/menu/home/default.htm> [Accessed December 2013].

6. Cammarata, L. \& Tedick, D.J. (2012). Balancing Content and Language in Instruction: The Experience of Immersion Teachers. // The Modern Language Journal, Vol. 96(ii), pp. 251-269. doi:10.1111/j.154000267902/12/251-269.

7. Chuchalin, A.I., Veledinskaja, S.B., Rojz, Sh.S. (2004) Formirovanie mul'tijazykovoj sredy - uslovija integracii universiteta $v$ mirovoe obrazovatel'noe prostranstvo. // Inzhenernoe obrazovanie, №2, s. 12-126.

8. Coonan, C.M. (2007) Insider Views of the CLIL Class through Teacher SelfObservation-Introspection. // International Journal of Bilingual Education 
and Bilingualism 10, Vol. 5, pp. 625-46.

9. Coyle, D. (2007) Content and Language Integrated Learning: Towards a Connected Research Agenda for CLIL Pedagogies. // International Journal of Bilingual Education and Bilingualism, Vol. 10(5), pp. 543-562. DOI:10.2167/beb459.0.

10. Dalton-Puffer, C. (2007) Discourse in Content and Language Integrated Learning (CLIL) Classrooms. Amsterdam: John Benjamins. p. 330. Available at: <https://doi.org/10.1177/1362168809341521> [Accessed January 2014].

11. Dalton-Puffer, C. (2011) Annual Review of Applied Linguistics, Vol. 31, pp. 182-204. Cambridge: CUP, doi: 10.1017/S0267190511000092.

12. Dalton-Puffer, C., Nikula, T. \& Smit, U. (2010) Language Use and Language Learning in CLIL: Current Findings and Contentious Issues. / Ed. by C. Dalton-Puffer, T. Nikula, \& U. Smit. Amsterdam: John Benjamins, pp. 279291.

13. Gajo, L. (2007) Linguistic Knowledge and Subject Knowledge: How Does Bilingualism Contribute to Subject Development? // International Journal of Bilingual Education and Bilingualism. Vol. 10(5), pp. 563-581.

14. Halliday, M.A.K. and Martin, J.R. (1993) Writing Science: Literacy and Discursive Power. Pittsburgh: University of Pittsburgh Press. pp. 4-6, 8-11.

15. Krashen, S.D. (1985) The Input Hypothesis: Issues and implications. New York: Longman.

16. Long, M.H. (1996) The Role of the Linguistic Environment in Second Language Acquisition. // Handbook of Second language Acquisition. / Ed. by W.C. Ritchie, \& T.K. Bhatia. New York: Academic Press, pp. 413-468.

17. Maljers, A., Marsh, D., Wolff, D. (2007) Windows on CLIL. Content and Language Integrated Learning in the European Spotlight. Alkmaar: European Platform for Dutch Education. Available at: $<$ https://www.researchgate.net/publication /290828891> [Accessed May 2017].

18. Marsh, D. (2005) Adding Language without Taking Away. Guardian Weekly, April 8.

19. Marsh, D. (2008) Language Awareness and CLIL. // Encyclopedia of 
Language and Education. Knowledge about Language, 2nd edition, Volume 6, New York, Springer Science+Business Media LLC. / Ed. by J. Cenoz and N.H. Hornberger.

20. Marsh, D. (2009) CLIL for a Knowledge Society. Available at: $<$ http://www.youtube.com/watch?gl=GB\&hl=enGB\&v=TGnkEMjBg4g\&fea ture $=$ related $>$ [Accessed September 2018].

21. Marsh, D. (2011) CLIL/EMILE. The European Dimension. Actions, Trends, and Foresight Potential. Jyva Skyla: University of Jyva Skyla.

22. Marsh, D., Marsland, B. (1999) CLIL Initiatives for the Millennium. Continuing Education Centre: University of Jyväskylä.

23. Mehisto, P. (2008) CLIL Counterweights: Recognizing and Decreasing Disjuncture in CLIL. // International Journal of Bilingual Education and Bilingualism 1/1, pp. 93-119.

24. Mehisto, P., Marsh, D. and Frigols, M-J. (2008) Uncovering CLIL: Content and Language Integrated Learning in Bilingual and Multilingual Education. Macmillan Education.

25. Pérez-Cañado, M.L. (2011) CLIL Research in Europe: Past, Present and Future. Available at: <https://www.researchgate.net/publication/254242 336> [Accessed January 2014].

26. Piet Van de Craen, Mondt, K., Allain, L., Gao, Y. (2007) Why and How CLIL Works. An Outline for a CLIL Theory". // CLIL Special Issues 2. Vol.16 (3).

27. Programma povyshenija konkurentosposobnosti NIU TPU sredi vedushchikh mirovykh nauchno-obrazovatel'nykh centrov. Available at: <http://tpu.ru/today/programs/viu> [Accessed December 2017].

28. Smith, K. (2005) Is This the End of the Language Class? // Guardian Weekly, January 21, 2005. Available at: <http://education.guardian.co.uk/ tefl/teaching/ story/0,15085,1394830,00.html> [Accessed September 2018].

29. Swain, M. (1995) Three Functions of Output in Second Language Learning. // Principle and Practice in Applied Linguistics: Studies in honour of H.G. Widdowson. / Ed. by G. Cook \& B. Seidlhofer. Oxford: OUP, pp. 125-144.

30. Tan, M. (2011) Mathematics and Science Teachers' Beliefs and Practices 
Regarding the Teaching of Language in Content Learning.// Language Teaching Research 15/3, pp. 325-42.

31. Ting, T. (2010) In Focus. CLIL Appeals to How the Brain Likes Its Information: Examples from CLIL-(Neuro) Science. // International CLIL Research Journal. Vol. 1(3).

32. Ting, T. (2011) CLIL ...Not Only Not Immersion But Also Much More than the Sum of Its Parts. // ELT Journal 65 (3), pp. 314-317. doi:10.1093/elt/ccr026.

33. Wesche, M.B. (2010) Content-Based Second Language Instruction. // The Oxford Handbook of Applied Linguistics. / Ed. by R.B. Kaplan. Oxford: OUP, pp. 275-293.

34. Wiesemes, R. (2009) Developing Theories of Practices in CLIL: CLIL as Post-Method Pedagogies? // Content and Language Integrated Learning: Evidence from Research in Europe. / Ed. by Y. Zarobe, and R. Ratalan. Bristol, UK: Multilingual Matters, pp. 41-59.

35. Zydatiß, W. (2012) Linguistic Thresholds in the CLIL Classroom? The Threshold Hypothesis Revisited. // International CLIL Research Journal, 1/4. Available at: <http://www.icr.eu.> [Accessed June 2017].

\section{CLIL-p npultu inpupulqui utepnqupuinıpjnı\&.}

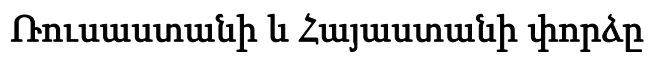

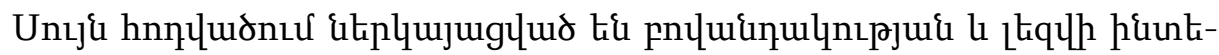

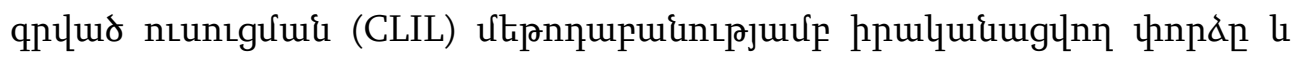

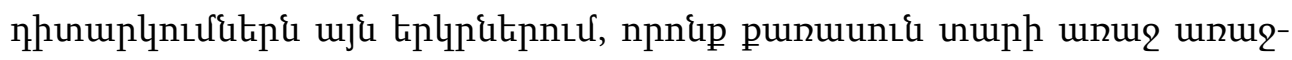

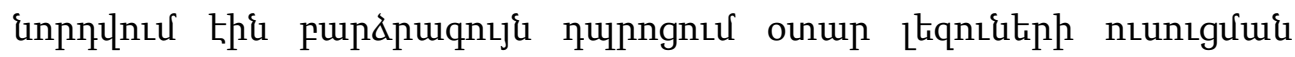

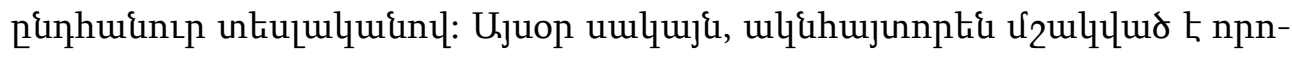

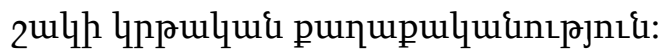

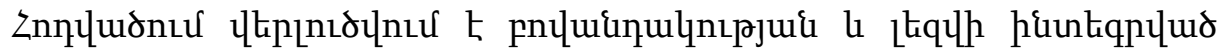

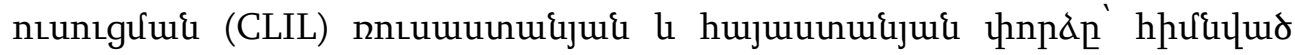

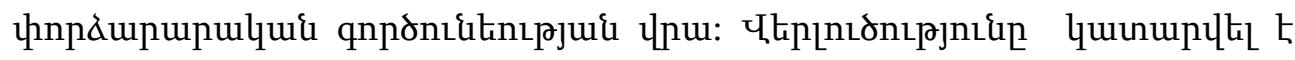

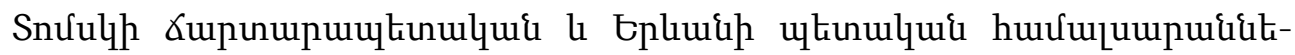




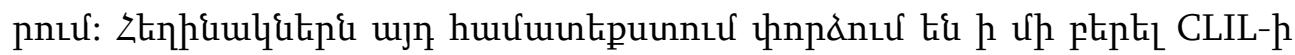

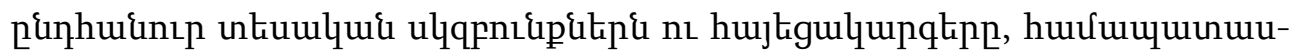

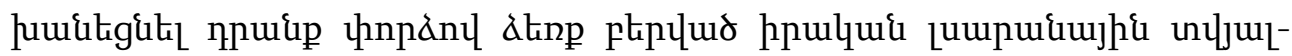

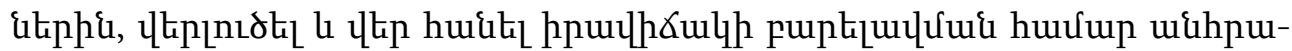

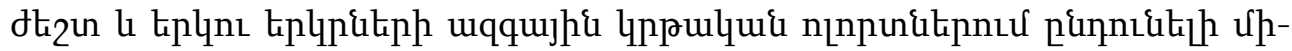

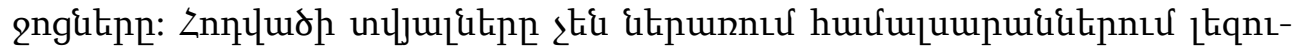

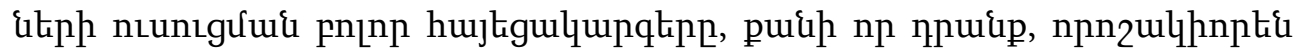
upunugn

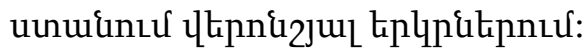

Received by the Editorial Board 24.01.2019

Recommended for publication by the reviewers 12.03.2019

Accepted for print 22.04.2019 